\title{
Avaliação comparativa de agentes coagulantes químico e natural no processo de clarificação águas servidas
}

O reúso de efluentes vem sendo estudado e tem como propósito reduzir a demanda sobre os mananciais, substituindo a água potável por uma água de qualidade inferior. Dentre as atividades que mais utilizam água, gerando cargas de sólidos totais, estão a lavagem de automóveis e de roupas, utilizando de coagulantes como tratamento. Este trabalho objetivou a comparação da aplicabilidade do sulfato de alumínio e das sementes de Moringa oleífera, no processo de coagulação dos efluentes. As amostras foram coletadas em uma lava a jato e uma residência localizados no Município de Sumé-PB, sendo aplicados como coagulantes o sulfato de alumínio e sementes de moringa em solução. Aplicou-se o planejamento fatorial 22, com três repetições no ponto central, verificando a influência do tempo e da quantidade dos coagulantes sobre a turbidez, o pH e a condutividade elétrica. Os resultados para o efluente de lava a jato demonstraram uma redução na turbidez de até $94 \%$, utilizando o coagulante natural, e até $96 \%$, para o sulfato de alumínio, que proporcionou a redução de $\mathrm{pH}$ e aumento da condutividade elétrica. Analisando os resultados para o efluente de lavagem de roupas, houve uma redução na turbidez de até $92 \%$, utilizando a solução de moringa, e até $70 \%$, para o sulfato de alumínio, com redução no $\mathrm{pH}$. Com um grau de confiança de $95 \%$, verificou-se que para a turbidez, quando se utilizou o sulfato de alumínio, os dois fatores e a interação foram estatisticamente significativos, enquanto para a moringa, apenas o tempo apresentou efeito significativo.

Palavras-chave: Moringa oleífera; Sulfato de alumínio; Turbidez; Reutilização; Planejamento fatorial.

\section{Comparative evaluation of chemical and natural coagulant agents in the process of served water clarification}

\begin{abstract}
The reuse of effluents has been studied and aims to reduce the demand on water sources, replacing drinking water with water of inferior quality. Among the activities that use water the most, generating loads of total solids, are washing cars and clothes, using coagulants as treatment. This work aimed to compare the applicability of aluminum sulfate and Moringa oleifera seeds in the effluent coagulation process. The samples were collected in a car wash and in a residence located in Sumé-PB, with aluminum sulfate and moringa seeds in solution being applied as coagulants. Factorial design $2^{2}$ was applied, with three repetitions at the central point, verifying the influence of time and the amount of coagulants on turbidity, $\mathrm{pH}$ and electrical conductivity. The results for the car wash effluent demonstrated a reduction in turbidity of up to $94 \%$, using the natural coagulant, and up to $96 \%$, for aluminum sulfate, which provided a reduction in pH and an increase in electrical conductivity. Analyzing the results for the clothes washing effluent, there was a reduction in turbidity of up to $92 \%$, using the moringa solution, and up to $70 \%$, for aluminum sulfate, with a reduction in $\mathrm{pH}$. With a $95 \%$ confidence level, it was found that for turbidity, when aluminum sulfate was used, the two factors and the interaction were statistically significant, while for moringa, only time had a significant effect.
\end{abstract}

Keywords: Moringa oleífera; Aluminum sulfate; Turbidity; Reuse; Factorial design.

Topic: Engenharia Ambiental

Reviewed anonymously in the process of blind peer
Received: 06/07/2021

Approved: 28/07/2021
Crisóstomo Hermes Soares Trajano da Silva (iD) Universidade Federal de Campina Grande, Brasil http://lattes.cnpq.br/8615601141183700

http://orcid.org/0000-0003-2736-4157

cristrajanodm@hotmail.com

Bruno Rafael Pereira Nunes (iD

Universidade Federal de Campina Grande, Brasil

http://lattes.cnpq.br/7697366969624190

http://orcid.org/0000-0002-4496-4122

bruno.rafael@professor.ufcg.edu.br

Mycarla Míria Araújo de Lucena (iD

Universidade Federal de Campina Grande, Brasil

http://lattes.cnpq.br/7697366969624190

http://orcid.org/0000-0002-3093-7625

mycarlalucena@gmail.com
Rick Anderson Freire Mangueira (iD)

Universidade Federal de Campina Grande, Brasil

http://lattes.cnpq.br/2917775158391373

http://orcid.org/0000-0001-5891-3580

rickanderson0310@yahoo.com.br
Referencing this:

SILVA, C. H. S. T.; NUNES, B. R. P.; MANGUEIRA, R. A. F.. Avaliação comparativa de agentes coagulantes químico e natural no processo de clarificação águas servidas. Revista Ibero Americana de Ciências Ambientais, v.12, n.7, p.253-263, 2021. DOI: http://doi.org/10.6008/CBPC2179-6858.2021.007.0024 


\section{INTRODUÇÃO}

A água é um recurso natural indissociável a vida humana, fundamental ao desenvolvimento econômico e ao bem-estar social, tendo uma infinidade de usos, dos mais simples aos mais complexos. A água participa de diversas atividades, seja no uso direto ou em setores vinculados ao fornecimento de produtos e serviços para abastecimento humano (VOET et al., 2014).

O uso da água tem aumentado em todo o mundo em cerca de $1 \%$ ao ano desde os anos 80 , impulsionado pelo crescimento populacional, desenvolvimento socioeconômico e mudanças nos padrões de consumo (ANA, 2017).

O desequilíbrio pluviométrico tem conduzido a sociedade a mudar seus hábitos sobre a demanda de águas potáveis e utilizando o reúso da água como alternativa para essa crise (DANTAS et al., 2019). Vários estudos vêm sendo realizados com o objetivo de determinar métodos que sejam sustentáveis e eficazes no tratamento de águas residuárias e que possibilitem a sua reutilização (SANTANA et al., 2019). Enquadram-se nesse contexto as águas provenientes de chuveiros, pias de cozinha, máquinas de lavar e lavagem de automóveis, que sozinha pode produzir, em média de 150 e 600 litros de águas residuárias, denominadas águas cinzas (GÖNDER et al., 2017). O reúso pode proporcionar a economia de grandes volumes de água potável, além gerar benefícios ambientais.

Entre as alternativas encontradas para minimizar o problema relativo à qualidade das águas residuárias, a adição de coagulantes junto ao efluente em que se busca reduzir a concentração de sólidos em suspensão, ou seja, um padrão aceitável ao consumidor, tem sido bastante aplicado (CHEN et al., 2018; MEGERSA et al., 2019).

Os coagulantes têm como principal função desestabilizar as partículas suspensas, formando coágulos, facilitando o processo de sedimentação diminuindo a turbidez e a cor (CHEN et al., 2018; MEGERSA et al., 2019). Na prática, o tratamento da água por coagulação é realizado pela adição de determinada quantidade de coagulantes, como sais de alumínio ou ferro, que em solução são dissociados na forma iônica trivalente, hidrolisados e acabam formando complexos carregados positivamente altamente interativos com os coloides com carga negativa (SILLANPÄÄ et al., 2018). Apesar do baixo custo e da alta eficiência na remoção de impurezas, esses coagulantes apresentam algumas desvantagens, como propriedades corrosivas e geram grandes quantidades de lodo, que podem conter ácido clorídrico, acarretando prejuízos para a fauna local (PALEARI, 2014). A exposição humana aos sais alumínio, correlacionam com doenças neurodegenerativas como Parkinson e Alzheimer (LIMA JÚNIOR et al., 2018).

Em função da obtenção de métodos alternativos houve um crescente interesse em biocoagulantes, os quais destacam-se as sementes de Moringa oleifera, sendo aplicadas como coagulante em águas residuais (VUNAIN et al., 2019; MOULIN et al., 2019). Segundo Vunain et al. (2019), a semente de moringa contém proteína solúvel que funciona como agente clarificador e desestabiliza as partículas na água, quando dissolvidas as sementes adquirem cargas positivas, atraem as cargas negativas, provenientes do material orgânico. Além disso, o pó da semente pode remover mais de $90 \%$ da carga bacteriana de amostras de água 
bruta (MOULIN et al., 2019).

Dentro desse contexto, justifica-se o desenvolvimento do presento trabalho, o qual objetivou a comparação da aplicabilidade do sulfato de alumínio e das sementes de Moringa oleifera, no processo de clarificação dos efluentes, uma vez que a prática do reúso deve ser estimulada e mais praticada, além da possibilidade da utilização de um coagulante natural de fácil acesso e baixo custo.

\section{MATERIAIS E MÉTODOS}

Todos os experimentos de clarificação foram realizados no laboratório de Qualidade de Água (LQA) do Centro de Desenvolvimento Sustentável do Semiárido (CDSA), na Universidade Federal de Campina Grande (UFCG) em Sumé-PB.

No preparo do Coagulante Natural, amostras das sementes de moringa (Moringa oleífera) foram coletadas nas dependências do Centro de Ciências e Tecnologia Agroalimentar (CCTA), da Universidade Federal de Campina Grande (UFCG), campus de Pombal-PB, e devidamente separadas das vagens (fruto), conforme apresentando na Figura 1.

Em seguida retiradas suas cascas e então pulverizadas em moinho de facas tipo Willey macro Tn650/1 com peneira, gerando partículas com diâmetro entre de 0,25 e 0,53 $\mu \mathrm{m}$, conforme apresentado na Figura 2. O processo de moagem das sementes foi realizado no Laboratório de Solos (LASOL), na UFCG, no Centro de Desenvolvimento Sustentável do Semiárido (CDSA), campus Sumé-PB.

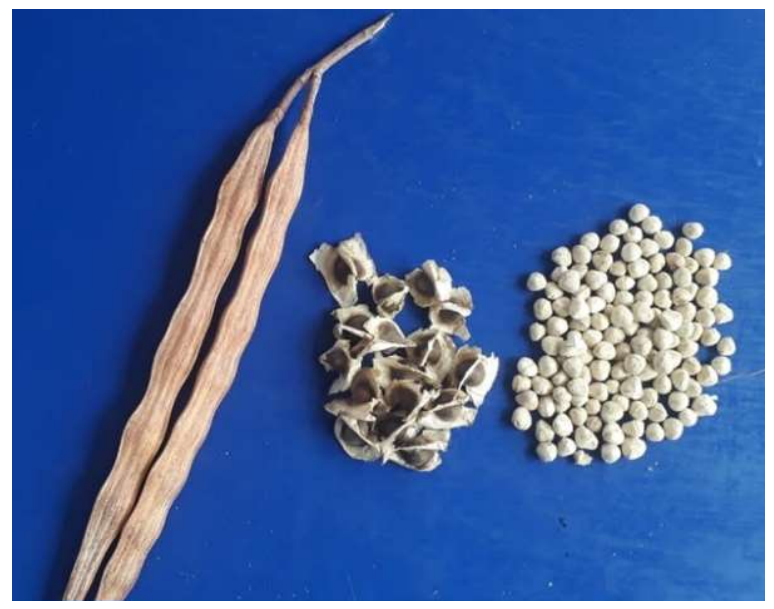

Figura 1: Sementes da Moringa oleífera antes da moagem.

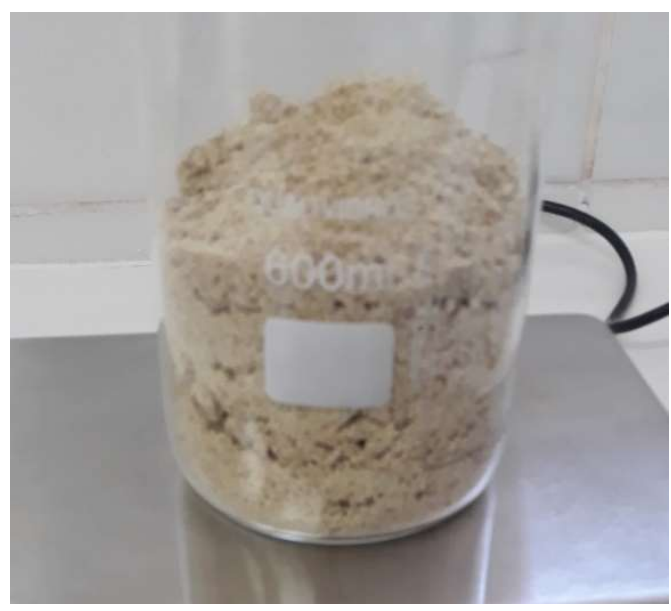

Figura 2: Sementes da Moringa oleífera após a moagem.

Amostras de água, provenientes da lavagem de automóveis, foram coletadas no Lavajato Sumeense, na cidade de Sumé-PB, conforme apresentado na Figura 3. Essas amostras foram armazenadas em galões de água mineral de 20 litros, previamente lavados, permitindo assim a preservação das propriedades físicoquímicas das amostras que foram avaliadas em tempo de até 24 horas após a coleta, como estabelecido pelo protocolo de análises de águas, descrito por Oliveira et al. (2006).

Amostras de águas cinzas, provenientes da lavagem de roupas em máquina de lavar, foram coletadas em uma residência no Município de Sumé-PB. Vale salientar que a coleta foi realizada em dois ciclos de lavagem da máquina, entre o modo 1 e 2, que corresponde ao enxague (molho) e lavagem (água e sabão). 


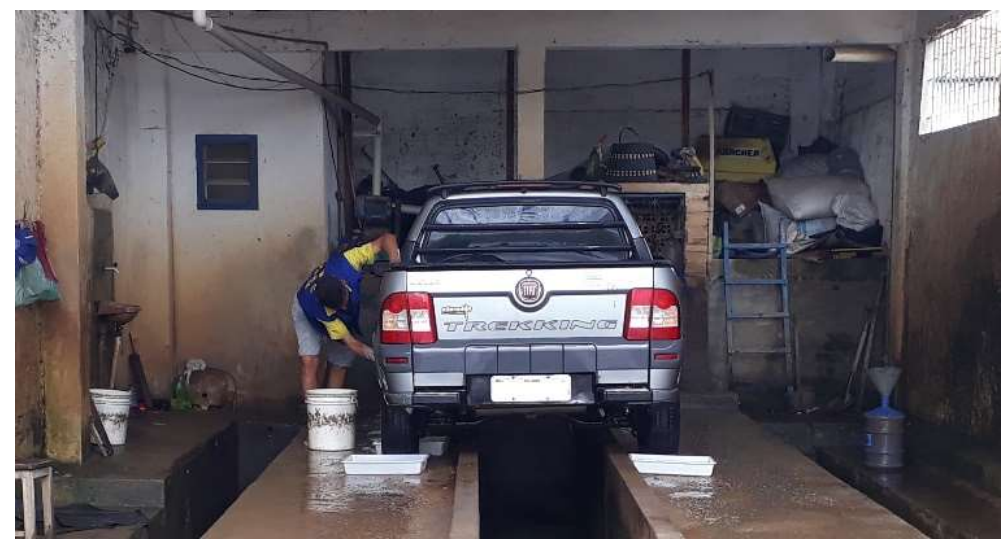

Figura 3: Processo de coleta do efluente gerado na lavagem de automóveis.

Os ensaios de clarificação dos efluentes foram conduzidos em garrafas PET, sendo utilizado como coagulante químico o Sulfato de Alumínio $\left(\mathrm{Al}_{2}\left(\mathrm{SO}_{4}\right)_{3}\right)$ em solução diluída, e como coagulante natural sementes de moringa descascadas e trituradas em moinho de facas, na forma de solução preparada na proporção de 20 gramas (g) de sementes para 1 litro (L) de água destilada. Tais proporções utilizadas foram baseadas no trabalho de Silva et al. (2020), em que o autor verifica a influência de agente coagulantes químico (Sulfato de alumínio) e natural (Moringa oleífera) no processo de coagulação de água de cisternas na cidade de SuméPB, analisando a influência das variáveis de entrada de tempo (30,60,0e $90 \mathrm{~min})$ e um volume de solução de sementes de Moringa que ao aplicar o planejamento experimental distribuiu em proporção de 10, 20 e 30 mL. Analisando essas influências sobre as variáveis em estudo, Silva et al. (2020), obteve uma redução de $63 \%$ na turbidez.

Para realização dos experimentos, aplicou-se o planejamento fatorial com dois fatores e três repetições no ponto central, visando verificar a influência das variáveis de entrada, tempo de tratamento e quantidade de coagulante, sobre as respostas turbidez, $\mathrm{pH}$ e condutividade elétrica. Os fatores avaliados e seus respectivos níveis, reais e codificados, encontram-se dispostos na Tabela 1.

Tabela 1: Matriz de planejamento com níveis reais e codificados das variáveis independentes.

\begin{tabular}{lllll}
\hline \multirow{2}{*}{ Ensaio } & \multicolumn{3}{l}{ Tempo de processo } & \multicolumn{2}{l}{ Quantidade de coagulante em solução } \\
\cline { 2 - 5 } & Codificado & Real & Codificado & Real \\
\hline 1 & -1 & $30 \mathrm{~min}$ & -1 & $20 \mathrm{~mL}$ \\
2 & +1 & $210 \mathrm{~min}$ & -1 & $20 \mathrm{~mL}$ \\
3 & -1 & $30 \mathrm{~min}$ & +1 & $100 \mathrm{~mL}$ \\
4 & +1 & $210 \mathrm{~min}$ & +1 & $100 \mathrm{~mL}$ \\
5 & 0 & $120 \mathrm{~min}$ & 0 & $60 \mathrm{~mL}$ \\
6 & 0 & $120 \mathrm{~min}$ & 0 & $60 \mathrm{~mL}$ \\
7 & 0 & $120 \mathrm{~min}$ & 0 & $60 \mathrm{~mL}$ \\
\hline
\end{tabular}

Alíquotas das amostras de água, antes e após os tratamentos, foram coletadas para realização das determinações físico-químicas. As análises físico-químicas das amostras foram realizadas no Laboratório de Qualidade de Água (LQA), no CDSA da UFCG.

Para determinar o pH, inicialmente realizou-se a calibração do pHmetro (Quimis-Q400 AS) com soluções tampão padrão de pH 4,0 e 7,0. Em seguida, os eletrodos foram inseridos nas amostras de água para leitura do $\mathrm{pH}$ e os dados foram registrados.

Para a determinação da condutividade elétrica das amostras de água, foi utilizado um condutivímetro 
(MS TECNOPON-mCA 150). Seus eletrodos foram devidamente lavados e após a calibração, foram imersos nas amostras de água, com isso os valores de condutividade foram coletados.

A turbidez foi medida através do turbidímetro (TECNOPON-CL800), comparando-se o espalhamento de um feixe de luz ao passar pela amostra com o espalhamento de um feixe de igual intensidade ao passar por uma suspensão padrão. Assim, coletou-se os dados referentes a este parâmetro para cada uma das amostras.

\section{RESULTADOS E DISCUSSÃO}

Os resultados obtidos a partir das análises físico-químicas, na determinação do pH, condutividade elétrica (CE) e turbidez, das amostras de efluente de lava jato, antes (B) e após os ensaios de tratamento, com as duas formas de coagulantes aplicados, encontram-se disponíveis na Tabela 2.

Tabela 2: Resultados das análises obtidos antes e após a etapa de tratamento das amostras.

\begin{tabular}{lllllll}
\hline \multirow{2}{*}{ Ensaio } & \multicolumn{2}{l}{ Coagulante Natural } & \multicolumn{3}{l}{ Coagulante Químico } \\
& pH & CE(ms/cm) & Turbidez (NTU) & pH & CE(ms/cm) & Turbidez (NTU) \\
\hline B & 7,30 & 0,33 & 839 & 7,98 & 0,35 & 1068 \\
1 & 7,20 & 0,34 & 181 & 2,74 & 4,78 & 178 \\
2 & 7,30 & 0,34 & 54 & 2,75 & 4,74 & 39 \\
3 & 6,97 & 0,36 & 225 & 2,19 & 16,21 & 171 \\
4 & 6,95 & 0,33 & 49 & 2,21 & 16,21 & 46 \\
5 & 7,28 & 0,29 & 97 & 2,36 & 11,11 & 77 \\
6 & 7,36 & 0,35 & 95 & 2,39 & 10,18 & 71 \\
7 & 7,33 & 0,34 & 94 & 2,34 & 10,62 & 68 \\
\hline
\end{tabular}

Avaliando os resultados obtidos para a condutividade das amostras de água tratada, ao utilizar o coagulante natural em solução, comparando-se com os valores observados nas amostras de água bruta, foram verificadas pequenas alterações, com variação de 0,29 a 0,36 ms/cm. Contudo, ao aplicar o coagulante químico em solução, foram verificados aumentos mais relevantes, alcançando-se o valor máximo de 16,21 $\mathrm{ms} / \mathrm{cm}$, ao usar $100 \mathrm{~mL}$ de coagulante.

Conforme descrito em Brasil (2014), a condutividade elétrica da água indica a sua capacidade em transmitir corrente elétrica em função da presença de substâncias dissolvidas, que podem se dissociar em ânions e cátions, com isso, quanto maior a concentração de íons em solução, maior deve ser a capacidade em conduzir corrente elétrica. Neste sentido, é possível propor que as alterações na condutividade das amostras tratadas aplicando o coagulante químico em solução, podem ter ocorrido devido a adição do íon alumínio ao meio, fazendo com que à presença do alumínio residual na água tenha gerado a elevação, principalmente nos ensaios onde o volume aplicado foi o maior (LOPES, 2014).

Em relação aos valores de $\mathrm{pH}$, foram verificadas pequenas alterações, ao serem aplicadas as sementes de moringa em solução, e uma grande redução ao utilizar o sulfato em solução, sendo, neste caso, alcançados valores entre 2,19 e 2,75.

Segundo Ribeiro (2015), quando o agente coagulante é adicionado na água ocorre uma dissociação iônica trivalente $\left(\mathrm{Al}^{3+}\right.$ e $\left.\mathrm{Fe}^{3+}\right)$ e reações de hidrólise que proporcionam o aumento do teor de íons $\mathrm{H}^{+} \mathrm{e}$ consequentemente diminuem o pH. Além disso, ocorre o aumento da dificuldade na formação de mais 
precipitado. Nestes casos, o valor do pH deve ser regulado pela presença de alguma substância alcalina, o que poderá influenciar diretamente o processo de coagulação, em particular na remoção da matéria orgânica natural e de substâncias químicas orgânicas sintéticas.

Os resultados obtidos na aplicação dos coagulantes para a remoção da turbidez permitiram verificar uma redução de 96,35\% quando foi utilizado o sulfato de alumínio em solução, para um tempo de 210 minutos (3,5 horas) e um volume de $20 \mathrm{~mL}$. Já para a solução de sementes de moringa, a redução da turbidez foi de $94,16 \%$, também para um tempo de 210 minutos (3,5 horas), utilizando $100 \mathrm{~mL}$ de solução. É possível verificar que os maiores percentuais de redução foram alcaçados nos ensaios onde o tempo de tratamento foi o maior.

Keogh et al. (2017), alcançaram $85 \%$ de redução da turbidez de amostras de água bruta, utilizando a moringa em forma de pó, para um tempo de 24 horas. Paula et al. (2014), também aplicaram as sementes de moringa no tratamento de amostras de água bruta e afirmaram que um tempo de tratamento mais prolongado se faz necessário para que ocorra a liberação das proteínas catiônicas ativas responsáveis pelo efeito do coagulante.

Os resultados obtidos a partir das análises físico-químicas, na determinação do $\mathrm{pH}$, condutividade elétrica (CE) e turbidez, das amostras de efluente de lavagem de roupa, antes (B) e após os ensaios de tratamento, com as duas formas de coagulantes aplicados, encontram-se disponíveis na Tabela 3.

Tabela 3: Resultados das análises obtidos antes e após a etapa de tratamento das amostras.

\begin{tabular}{|c|c|c|c|c|c|c|}
\hline \multirow{2}{*}{ Ensaio } & \multicolumn{3}{|c|}{ Coagulante Natural } & \multicolumn{3}{|c|}{ Coagulante Químico } \\
\hline & $\mathrm{pH}$ & $\mathrm{CE}(\mu \mathrm{s} / \mathrm{cm})$ & Turbidez (NTU) & $\mathrm{pH}$ & $\mathrm{CE}(\mu \mathrm{s} / \mathrm{cm})$ & Turbidez (NTU) \\
\hline$B$ & 10,30 & 178,5 & 233,0 & 10,04 & 168,9 & 210,0 \\
\hline 1 & 10,27 & 175,2 & 173,0 & 2,72 & 144,5 & 94,0 \\
\hline 2 & 10,61 & 176,7 & 60,0 & 2,72 & 146,8 & 69,0 \\
\hline 3 & 11,06 & 162,1 & 220,0 & 2,13 & 143,5 & 74,0 \\
\hline 4 & 9,73 & 159,1 & 21,0 & 2,06 & 148,2 & 63,0 \\
\hline 5 & 10,08 & 168,0 & 66,0 & 2,28 & 101,5 & 78,0 \\
\hline 6 & 10,10 & 168,5 & 76,0 & 2,29 & 105,5 & 77,0 \\
\hline 7 & 10,07 & 171,0 & 72,0 & 2,32 & 102,3 & 77,0 \\
\hline
\end{tabular}

Avaliando os resultados obtidos para a condutividade elétrica das amostras de água de lavagem de roupa tratada, comparando-se com os valores observados nas amostras de água bruta, independente do tipo de coagulante, foram verificadas pequenas variações.

Em relação aos valores de $\mathrm{pH}$, foram verificadas pequenas alterações, ao serem aplicadas as sementes de moringa em solução, e uma grande redução ao utilizar o sulfato de alumínio em solução, sendo, neste caso, alcançados valores entre 2,06 e 2,72. Percebe-se que o pH da água bruta para este tipo de efluente foi superior ao observado no efluente de lava a jato, sendo este parâmetro igual a 10,04, para a água coletada na lavagem de roupas. Monteiro et al. (2015), observaram pH médio de 8,3 para amostras de águas cinzas, justificando este valor pela quantidade de sabão utilizada neste processo.

Os resultados obtidos na aplicação dos coagulantes para a remoção da turbidez permitiram verificar uma redução de 70,00\% quando foi utilizado o sulfato de alumínio em solução, para um tempo de 210 minutos (3,5 horas) e um volume de $20 \mathrm{~mL}$. Já para a solução de sementes de moringa, a redução da turbidez 
foi de 90,99\%, também para um tempo de 210 minutos (3,5 horas), utilizando $100 \mathrm{~mL}$ de solução. É possível verificar que os maiores percentuais de redução foram alcançados nos ensaios onde o tempo de tratamento foi o maior.

Por meio da realização da análise estatística dos resultados, considerando-se um nível de confiança de $95 \%$, foi possível confirmar quais fatores exerceram influência sobre as respostas, ou seja, quais foram estatisticamente significativos.

Como forma de facilitar a compreensão de como os fatores podem influeciar as repostas e quais são mais importantes, foram construídos os diagramas de Pareto para os dois coagulantes aplicados e parâmetros físico-químicos avaliados. Este tipo de diagrama é um recurso utilizado na análise estatística que permite apresentar os resultados em uma ordem hierárquica, ajudando a identificar e avaliar quais parâmetros e interações são mais significativas sobre cada variável de resposta estudada (SILVA et al., 2015).

Nas Figuras 4 (a), (b) e (c), encotram-se os diagramas de Pareto dos efeitos padronizados em $p=0,05$, para o $\mathrm{pH}$, condutividade elétrica e turbidez, respectivamente, nos ensaios realizados aplicando o coagulante natural a base de sementes de moringa, na clarificação do eflunte de lava a jato.
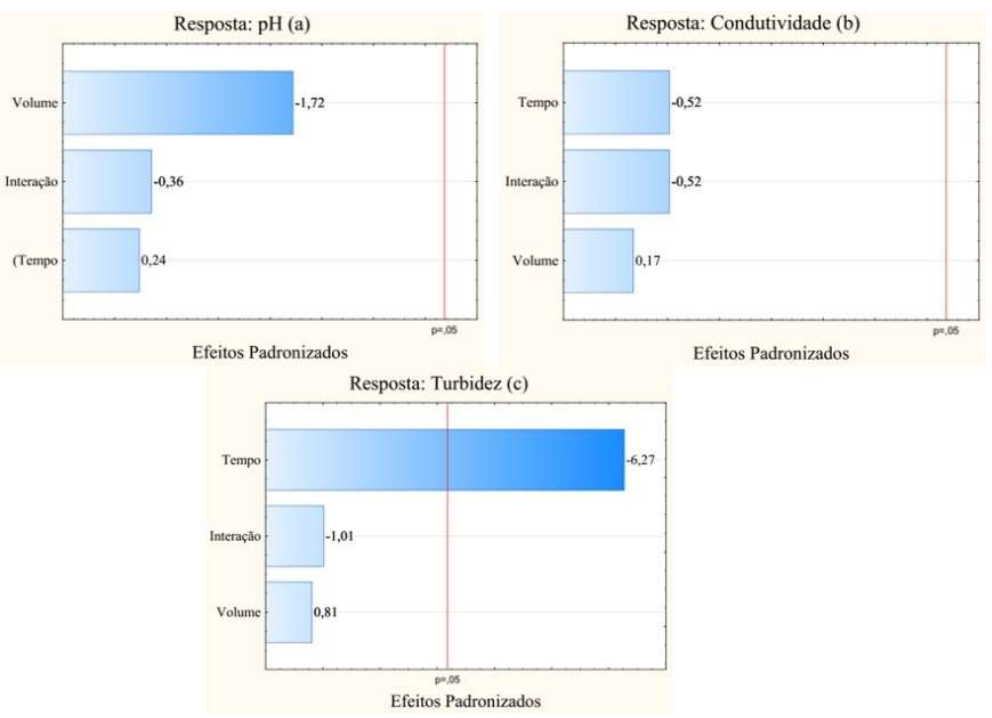

Figura 4: Diagramas de Pareto para os efeitos padronizados em $\mathrm{p}=0,05$, para as repostas $\mathrm{pH}$ (a), condutividade elétrica (b) e turbidez (c), aplicando o coagulante natural.

Avaliando os diagramas de Pareto e os valores dos efeitos dos fatores, verifica-se que apenas o tempo foi estatisticamente significativo sobre a resposta turbidez, sendo que este efeito foi negativo, o que representa que um aumento do período de tratamento pode permitir a redução da turbidez, gerando uma água tratada com menor teor de sólidos em suspensão.

Nas Figuras 5 (a), (b) e (c), encotram-se os diagramas de Pareto dos efeitos padronizados, para todas as respostas, aplicando o sulfato de alumínio em solução, na clarificação do eflunte de lava a jato.

Avaliando os diagramas de Pareto e os valores dos efeitos, verifica-se que o volume de coagulante foi um fator estatisticamente significativo sobre as repostas $\mathrm{pH}$ e condutividade elétrica. $\mathrm{O}$ efeito foi negativo para o pH, o que representa que um maior volume irá gerar a redução do parâmetro, gerando uma água tratada com maior acidez. Em relação a condutividade elétrica o efeito foi positivo, o que permite afirmar 
que o aumento do volume de coagulante irá produzir uma água tratada com maior condutividade elétrica. As causas para estas alterações foram explicadas anteriormente, quando os resultados contidos na Tabela 2 foram apresentados.
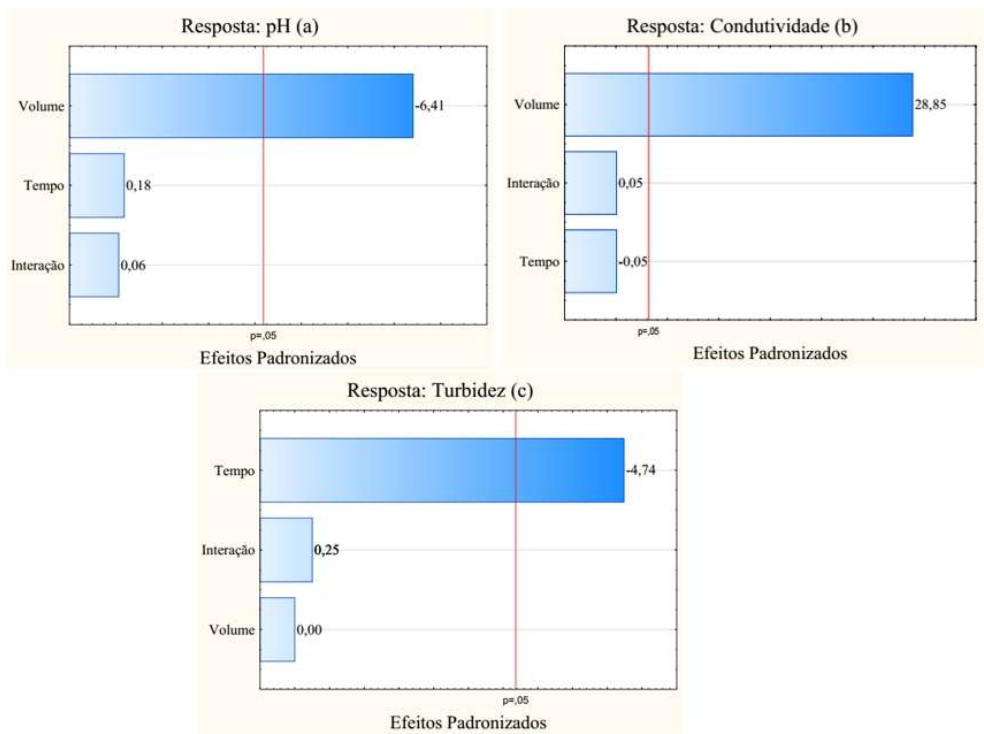

Figura 5: Diagramas de Pareto para os efeitos padronizados em $p=0,05$, para as repostas $\mathrm{pH}(\mathrm{a})$, condutividade elétrica (b) e turbidez (c), aplicando o sulfato de alumínio em solução.

Ao avaliar o efeito dos fatores sobre a turbidez, verifica-se que o tempo foi estatisticamente significativo e que o valor observado também foi negativo, portanto, um maior tempo de tratamento irá proporcionar uma maior redução na turbidez do efluente a ser tratado.

Nas Figuras 6 (a), (b) e (c), encotram-se os diagramas de Pareto dos efeitos padronizados em $p=0,05$, para o $\mathrm{pH}$, condutividade elétrica e turbidez, respectivamente, nos ensaios realizados aplicando o coagulante natural a base de sementes de moringa, na clarificação do eflunte da lavagem de roupas.
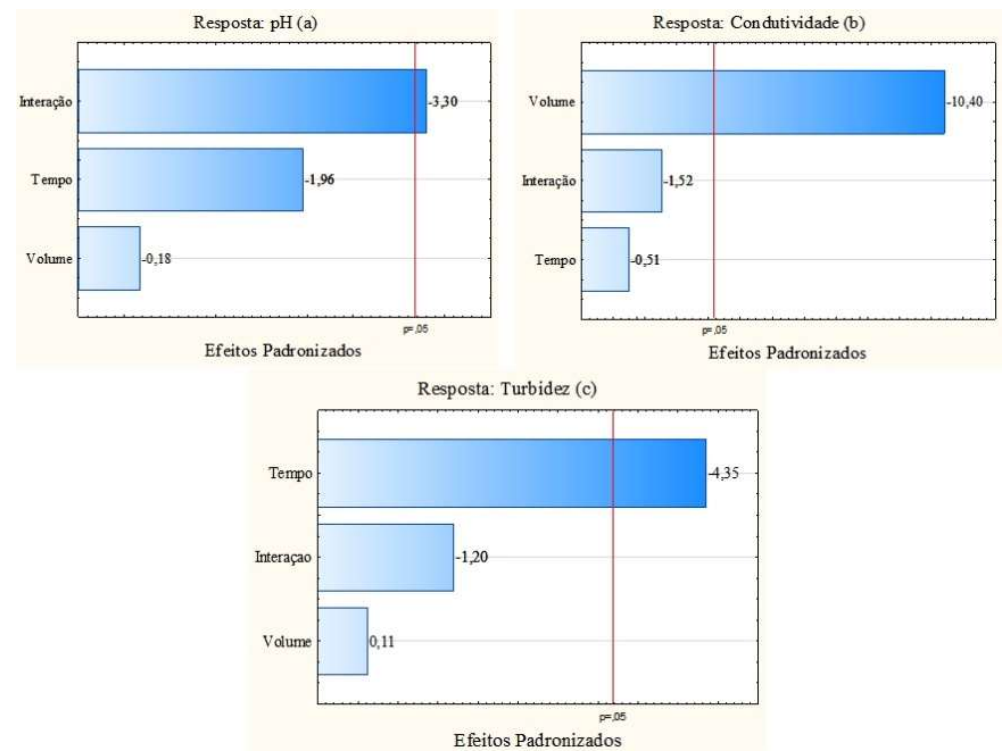

Figura 6: Diagramas de Pareto para os efeitos padronizados em $p=0,05$, para as repostas $\mathrm{pH}$ (a), condutividade elétrica (b) e turbidez (c), aplicando o coagulante natural.

Avaliando a Figura 6, verifica-se que a interação entre os fatores foi estatisticamente significativa sobre o pH. Em relação à condutividade elétrica, apenas o volume de coagulante foi significativo, com efeito 
negativo. Para turbidez, apenas o tempo foi estatisticamente significativo, sendo também negativo, com isso, um aumento deste fator pode gerar a redução da turbidez, gerando uma água tratada com menor teor de sólidos em suspensão. Nas Figuras 7 (a), (b) e (c), encotram-se os diagramas de Pareto dos efeitos padronizados, para todas as respostas, aplicando o sulfato de alumínio em solução, na clarificação do eflunte da lavagem de roupas.
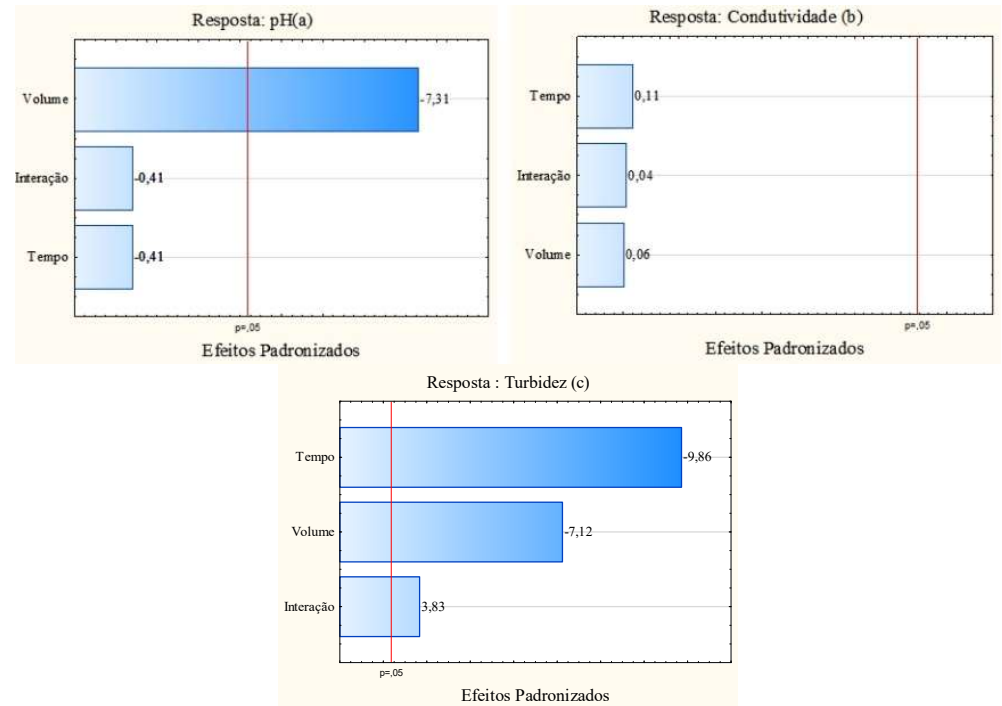

Figura 7: Diagramas de Pareto para os efeitos padronizados em $p=0,05$, para as repostas $\mathrm{pH}(\mathrm{a})$, condutividade elétrica (b) e turbidez (c), aplicando o sulfato de alumínio em solução.

Ao avaliar o efeito dos fatores sobre a turbidez, verifica-se que o tempo e o volume foram estatisticamente significativos e que os valores observados também foram negativos. Além disso, a interação entre os dois fatores também tem efeito sobre esta resposta. Portanto, dentro da faixa estudada, um maior tempo de tratamento e um maior volume de solução irão proporcionar uma maior redução na turbidez do efluente a ser tratado.

Assim, em virtude dos resultados obtidos, e utilizando a análise estatística como ferramenta, fica comprovado que ao tratar os efluentes gerados nos processos de lavagem de veículos e de roupas, há a possibilidade da substituição do coagulante convencional, sulfato de alumínio, pelo coagulante natural obtido a partir das sementes de Moringa oleifera.

O coagulante natural proporcionou, em média, $90 \%$ de remoção da turbidez, sendo estes percentuais de remoção satisfatórios, quando comparado com os resultados obtidos aplicando o sulfato de alumínio, o qual é responsável por produzir um lodo inorgânico, que pode ser corrosivo, devido a redução no pH. Ademais, a aplicação da moringa, por se tratar de um produto natural e biodegradável, pode ser considerada uma alternativa eficiente que possibilita o reúso da água havendo uma economia em relação ao custo do produto e também a redução dos impactos ambientais.

\section{CONCLUSÕES}

Para as condições estudadas, é possível afirmar que as sementes de Moringa oleifera, em solução, podem ser aplicadas como coagulante no tratamento de águas residuárias provenientes das lavagens de 
veículos e de roupas, reduzindo os teores de turbidez em até $95 \%$, valores semelhantes aos obtidos com o coagulante químico, gerando a possibilidade de uso alternativo dessas águas em aplicações não potáveis, com a vantagem de ser um produto natural de baixo custo, boa disponibilidade e sem promover alterações significativas no $\mathrm{pH}$ e na condutividade elétrica das amostras.

Por meio da aplicação do planejamento fartorial, e da análise estatística dos resultados, pode-se afirmar que, para as condições aplicadas, a variável tempo apresenta efeito sobre a turbidez, em todos os ensaios realizados, sendo comprovado que um maior tempo de tratamento proporciona uma maior redução da turbidez, independente do tipo de efluente tratado.

\section{REFERÊNCIAS}

ANA. Agência Nacional de Águas. Conjuntura dos recursos hídricos no Brasil 2017: relatório pleno. Brasília: ANA, 2017.

BRASIL. Ministério da Saúde. Fundação Nacional de Saúde. Manual de controle da qualidade da água para técnicos que trabalham em ETAS. Brasília: FUNASA, 2014.

CHEN, S.; YUAN, Z.; HANIGAN, D.; WESTERHOFF, P.; ZHAO, $\mathrm{H}$.; NI, J.. Coagulation behaviors of new covalently bound hybrid coagulants $(\mathrm{CBHyC})$ in surface water treatment. Separation and Purification Technology, v.192, p.322-328, 2018. DOI: https://doi.org/10.1016/j.seppur.2017.10.036

DANTAS, P. R.; CHAVES, M. T. L.; CAVALCANTE, D. M.; ALBUQUERQUE, W. G.; MEDEIROS, W. P.; BEZERRA, A. M. S. Reúso de água cinza tratada em sistema de alagado construído com resíduos da construção civil. Revista Verde de Agroecologia e Desenvolvimento Sustentável, Pombal, v.14, n.1, p.62-68, 2019. DOI:

https://doi.org/10.18378/rvads.v14i1.5819

GÖNDER, Z. B.; BALCIOGLU, G.; VERGILI, I.; KAYA, Y.. Electrochemical treatment of carwash wastewater using $\mathrm{Fe}$ and Al electrode: Techno-economic analysis and sludge characterization. Journal of Environmental Management, v.200, p.380-390, 2017. DOI:

https://doi.org/10.1016/j.jenvman.2017.06.005

KEOGH, M. B.; ELMUSHARAF, K.; BORDE, P.; McGUIGAN, K. G.. Evaluation of the natural coagulant Moringa oleifera as a pretreatment for SODIS in contaminated turbid water. Solar Energy, v.158, p.448-454, 2017. DOI: https://doi.org/10.1016/j.solener.2017.10.010

LIMA JÚNIOR, R. N.; ABREU, F. O. M. S.. Produtos Naturais Utilizados como Coagulantes e Floculantes para Tratamento de Águas: Uma Revisão sobre Benefícios e Potencialidades. Revista Virtual de Química, Niterói, v.10, n.3, p.709-735, 2018. DOI: https://doi.org/10.21577/1984-6835.20180052

LOPES, B. V.. Eficiência de Coagulantes na Remoção de Diferentes Concentrações de Ferro e Manganês para ETA Terras Baixas. Monografia (Bacharelado em Engenharia Ambiental e Sanitária) - Universidade Federal de Pelotas, Pelotas, 2014.

MEGERSA, M.; GACH, W.; BEYENE, A.; AMBELU, A.; TRIEST, L.. Effect of salt solutions on coagulation performance of Moringa stenopetala and Maerua subcordata for turbid water treatment. Separation and Purification Technology, v.221, p.319-324, 2019. DOI: https://doi.org/10.1016/j.seppur.2019.04.013

MONTEIRO, V. R. C.; SEZERINO, P. H.; PHILIPPI, L. S.. Caracterização e Tratamento de Água Cinza Residencial Empregando a Ecotecnologia dos Wetlands Construídos. Engenharia Ambiental, Espirito Santo do Pinhal, v.12, n.2, p.93-109, 2015.

MOULIN, M.; MOSSOU, E.; SIGNOR, L.; KIEFFER-JAQUINOD, S.; KWAAMBWA, H. M.; NERMARK, F.; GUTFREUND, P.; MITCHELL, E. P.; HAERTLEIN, M.; FORSYTH, V. T.; RENNIE, A. R.. Towards a molecular understanding of the water purification properties of Moringa seed proteins. Journal of Colloid and Interface Science, v.554, p.296-304, 2019. DOI: https://doi.org/10.1016/i.jcis.2019.06.071

OLIVEIRA, R.; SILVA, S. A.. Manual de análises físico químicas de águas de abastecimento e residuárias. Rio de Janeiro: ABES, 2006.

PAULA, H. M.; ILHA, M. S. O.; ANDRADE, L. S.. Concrete plant wastewater treatment process by coagulation combining aluminum sulfate and Moringa oleífera powder. Journal of Cleaner Production, v.76, p.125-130, 2014. DOI: https://doi.org/10.1016/i.jclepro.2014.04.031

PALEARI, T. H.. Natural coagulants and chemical coagulant for the treatment of wastewater of the soluble coffee industry. Monografia (Bacharelado em Engenharia ambiental) - Universidade Tecnológica Federal do Paraná, Londrina, 2014.

RIBEIRO, I.. Aplicação de coagulantes e floculantes orgânicos alternativos no pós-tratamento de efluente de laticínio. Monografia (Bacharelado em Engenharia Ambiental e Sanitária) - Universidade Tecnológica Federal do Paraná, Medianeira, 2015.

SANTANA, M. V. E.; CORNEJO, P. K.; RODRÍGUEZ-RODA, I.; BUTTIGLIERI, G.; COROMINAS, L.. Holistic life cycle assessment of water reuse in a tourist-based community. Journal of Cleaner Production, v.233, p.743-752, 2019. DOI: https://doi.org/10.1016/i.jclepro.2019.05.290

SILLANPÄÄ, M.; NCIBI, M. C.; MATILAINEN, A.; VEPSALAINEN, $M$.. Removal of natural organic matter in drinking water treatment by coagulation: A comprehensive review. 
Chemosphere, v. 190, p.54-71, 2018. DOI: https://doi.org/10.1016/i.chemosphere.2017.09.113

SILVA, C. H. S. T.; NUNES, B. R. P.; MEDEIROS, L. G.; PINHEIRO, M. A. M.; ALMEIDA, S. N. R.; PORTO, H. C.; LEAL, M. C.; PIRES, J. J. B.. Avaliação comparativa de agentes coagulantes químico e natural no processo de coagulação de águas de cisterna no município de Sumé-PB. Brazilian Journal of Development, São José dos Pinhais, v.6, n.1, p.5109-5116, 2020. DOI: https://doi.org/10.34117/bjdv6n1$\underline{369}$

SILVA, M. S. B.; DANTAS, S. L. A.. Planejamento Experimental para Análise de Parâmetros Utilizados da Injeção de Polímeros em Reservatório de Petróleo. In: CONGRESSO
NACIONAL DE ENGENHARIA DE PETRÓLEO, GÁS NATURAL E BIOCOMBUSTÍVEIS, 1. Anais. Campina Grande, 2015.

VUNAIN, E.; MASOAMPHAMBE, E. F.; MPEKETULA, P. M. G.; MONJEREZI, M.; ETALE, A.. Evaluation of coagulating efficiency and water borne pathogens reduction capacity of Moringa oleifera seed powder for treatment of domestic wastewater from Zomba, Malawi. Journal of Environmental Chemical Engineering, v.7, p.103-118, 2019. DOI: https://doi.org/10.1016/i.jece.2019.103118

VOET, D.; VOET, J.; PRATT, C. W.. Fundamentos de bioquímica: a vida em nível molecular. 4 ed. Porto Alegre: Artmed, 2014.

A CBPC - Companhia Brasileira de Produção Científica (CNPJ: 11.221.422/0001-03) detém os direitos materiais desta publicação. Os direitos referem-se à publicação do trabalho em qualquer parte do mundo, incluindo os direitos às renovações, expansões e disseminações da contribuição, bem como outros direitos subsidiários. Todos os trabalhos publicados eletronicamente poderão posteriormente ser publicados em coletâneas impressas sob coordenação da Sustenere Publishing, da Companhia Brasileira de Produção Científica e seus parceiros autorizados. Os (as) autores (as) preservam os direitos autorais, mas não têm permissão para a publicação da contribuição em outro meio, impresso ou digital, em português ou em tradução. 